\title{
PECS Block Provides Effective Postoperative Pain Management for Breast Cancer Surgery-A Retrospective Study
}

\author{
Ichikawa Yuki1 , Hironobu Ueshima ${ }^{2 *}$, Hiroshi Otake², Akira Kitamura1 \\ ${ }^{1}$ Department of Anesthesiology, Saitama Medical University International Medical Center, Saitama, Japan \\ ${ }^{2}$ Department of Anesthesiology, Showa University Hospital, Tokyo, Japan \\ Email: *ueshimhi@yahoo.co.jp
}

How to cite this paper: Yuki, I., Ueshima, H., Otake, H. and Kitamura, A. (2017) PECS Block Provides Effective Postoperative Pain Management for Breast Cancer Surgery-A Retrospective Study. International Journal of Clinical Medicine, 8, 198-203.

https://doi.org/10.4236/ijcm.2017.83019

Received: January 19, 2017

Accepted: March 28, 2017

Published: March 31, 2017

Copyright $\odot 2017$ by authors and Scientific Research Publishing Inc. This work is licensed under the Creative Commons Attribution International License (CC BY 4.0).

http://creativecommons.org/licenses/by/4.0/

\begin{abstract}
We investigated the efficacy of ultrasound-guided pectoral nerves (PECS) block for modified radical mastectomy surgery retrospectively. Methods: We measured that pain scores and the use of additional analgesic drugs were recorded in the postoperative care unit within 24 hours after the operation. Postoperative complications (i.e., nausea and vomiting) were noted. Results: Patients who received the PECS block under general anesthesia (PECS group) reported lower visual analog scale pain scores at $0,1,2,4,6,12,24$ hours after the operation than patients who did not receive PECS block under general anesthesia (control group). Moreover, the use of additional analgesic drugs during the first 24 hours after surgery was lower in the PECS group than in the control group. While in the postoperative care unit, the PECS group had less nausea and vomiting than the control group. Conclusion: The PECS block provides effective postoperative analgesia within the first 24 hours after breast cancer surgery.
\end{abstract}

\section{Keywords}

Pectoral Nerves Block, Postoperative Pain Management, Breast Cancer Surgery

\section{Introduction}

Acute postoperative pain following breast cancer surgery is often disregarded because the procedure is considered minimally invasive. However, if acute pain management is neglected, most patients will develop chronic post-mastectomy pain [1], which reduces quality of life.

To manage acute pain after breast cancer surgery, regional anesthesia is rec- 
ommended [1] [2] as fentanyl is associated with a risk of vomiting and nausea. Therefore, to avoid the risk of postoperative nausea and vomiting, the injection of fentanyl is discouraged. Regional anesthesia such as thoracic epidural block (TEB) and thoracic paravertebral block (TPVB) can provide effective postoperative pain after breast cancer surgery [3] [4]. However, as the TEB and the TPVB are deep nerve blocks, we are hesitant to perform these techniques.

Pectoral nerves (PECS) block, previously described by Blanco et al. [5] [6], can anesthetize the intercostobrachial, lateral cutaneous branch, medial cutaneous nerve of the arm and forearm, and long thoracic and thoracodorsal nerves, which is analgesic at the lateral mammary area. Therefore, we hypothesized that the combination of general anesthesia and PECS block would provide effective analgesia for breast cancer surgery. However, there are a few reports of the efficacy of PECS block [7]. A research purpose in this study was to investigate about the efficacy of ultrasound-guided PECS block for breast cancer surgery.

\section{Materials and Methods}

Institutional review board approval was obtained (IRB number 14 - 167. February 2015), and we performed a retrospective examination of medical records of all patients who underwent for breast cancer surgery between April 1, 2014 and September 30, 2014. Perioperative data were collected, including age, height, weight, American Society of Anesthesiologists classification, operation time, anesthesia time, intraoperative fentanyl consumption, visual analog scale pain scores (at $0,1,2,4,6,12,24$ hours postoperatively), additional analgesic drugs used, and the complications (i.e., nausea and vomiting) within 24 hours after the operation. This study selected only breast cancer surgeries performed at the lateral site and modified radical mastectomy. In addition, we excluded some cases involving secondary surgery, bilateral breast cancers and performed regional anesthesia except the PECS block. Selected patients were divided into 2 groups. Patients in the PECS group received a PECS block after induction of anesthesia, whereas patients in the control group received no PECS block.

All surgeries were performed at Saitama Medical University International Medical Center. All PECS blocks were performed by the staff regional anesthesiologist. PECS block was conducted after the induction of anesthesia and was performed by administering $10 \mathrm{~mL}$ of $0.25 \%$ levobupivacaine between the pectorals major and pectorals minor at the third left rib and $20 \mathrm{~mL}$ of $0.25 \%$ levobupivacaine between the pectoralis minor and serratus muscles at the forth left rib by using a $50 \times$ high-frequency linear probe with the S-Nerve ultrasound system (SonoSite FUJIFILM, America) [4]. The analgesic drugs used in the perioperative period were remifentanil and fentanyl. Intravenous acetaminophen (1 g) or intravenous flurbiprofen $(50 \mathrm{mg}$ ) was administered in all patients at the end of each operation. All patients were extubated in the operating room then transferred to the postanesthesia care unit (PACU).

In the PACU, patients were managed with a standard monitor, pain scores were measured by using a visual analog scale (VAS) at $0,1,2,4,6,12,24$ hours 
postoperatively by a nurse. If the patients reported operative wound pain, the lead physician ordered intravenous acetaminophen $(1 \mathrm{~g})$. If acetaminophen was ineffective, $15 \mathrm{mg}$ intravenous pentazocine hydrochloride was started. A metoclopramide $(10 \mathrm{mg})$ was injected to manage nausea and vomiting.

Postoperative pain scores (at $0,1,2,4,6,12,24$ hours), the amount of acetaminophen used within 24 hours after operation, and the number of patients complained of nausea and vomiting within 24 after the operation were recorded.

Statistical analysis was performed utilizing JMP 11 (SAS Institute Inc., Cary, NC, USA). Statistical tests included the Mann-Whitney's $U$-test and $\chi^{2}$ test. Demographic data were expressed as mean (standard deviation, SD). Measurement data were expressed as mean (range). The level of significance for both tests was set at $P<0.05$.

\section{Results}

During the study period, 254 patients (115 PECS and 139 controls) underwent breast cancer surgery; 8 patients in the PECS group and 17 patients in the control group were excluded because of some cases involving secondary surgery, bilateral breast cancers and performed regional anesthesia except the PECS block (Figure 1). Patients demographics and duration of surgery were comparable (Table 1). Fentanyl consumption was lower in the PECS group than in the control group. VAS scores were significantly lower in the PECS group than in the control group (Figure 2). The amount of additional acetaminophen $(1 \mathrm{~g})$ used was lower in the PECS group than in the control group $(P=0.0012)$ (Table 2). No patients required additional analgesic including the addition of intravenous pentazocine hydrochloride $(15 \mathrm{mg})$.

Table 1. Demographic date.

\begin{tabular}{cccc}
\hline Variable mean (SD) & PECS group $(\mathrm{n}=107)$ & Control group $(\mathrm{n}=122)$ & $P$ \\
\hline Age, y & $57.36(12.6)$ & $57.09(13.0)$ & 0.98 \\
Weight, kg & $56.59(10.1)$ & $56.16(9.4)$ & 0.69 \\
Height, cm & $155(6.6)$ & $154(5.6)$ & 0.19 \\
ASA class I, II, III, IV & $49,56,2,0$ & $52,66,4,0$ & \\
Duration of surgery, min & $92(38)$ & $94(32)$ & 0.32 \\
Duration of Anesthesia, min & $130(41)$ & $132(35)$ & 0.49 \\
Intraoperative & $280.37(44.38)$ & $304.91(60.35)$ & 0.0011 \\
fentanyl consumption, $\mu \mathrm{g}$ & & & \\
\hline
\end{tabular}

Table 2. Date within 24 after operation.

\begin{tabular}{cccc}
\hline Variable & $\begin{array}{c}\text { PECS group } \\
(\mathrm{n}=107)\end{array}$ & $\begin{array}{c}\text { Control group } \\
(\mathrm{n}=122)\end{array}$ & $P$ \\
\hline Additional acetaminophen 1 g, number of dose & $1.4(0.6)$ & $2.2(0.8)$ & 0.0012 \\
Nausea and vomiting, number of patient & 11 & 27 & 0.016 \\
\hline
\end{tabular}




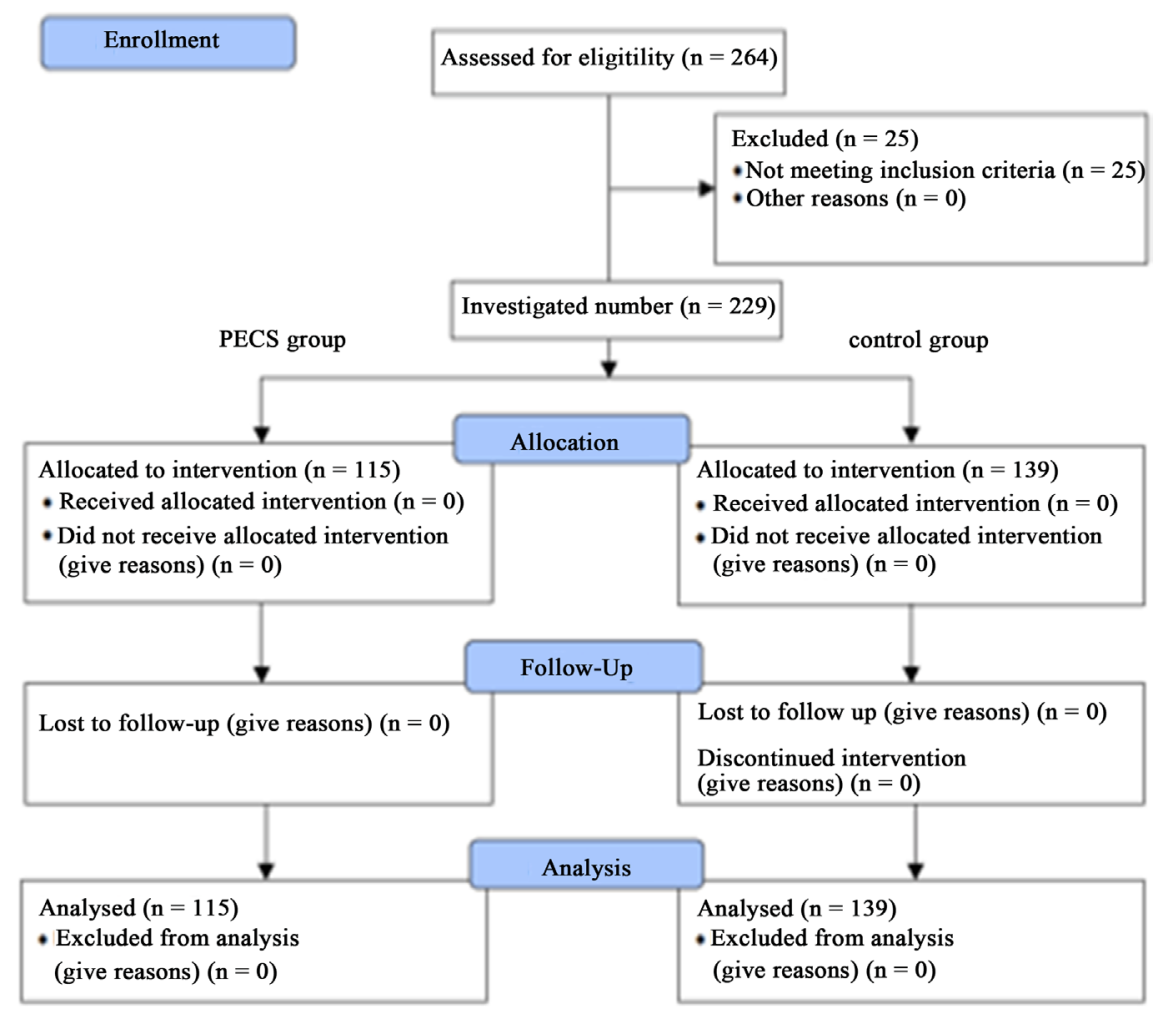

Figure 1. Flowchart of this study.

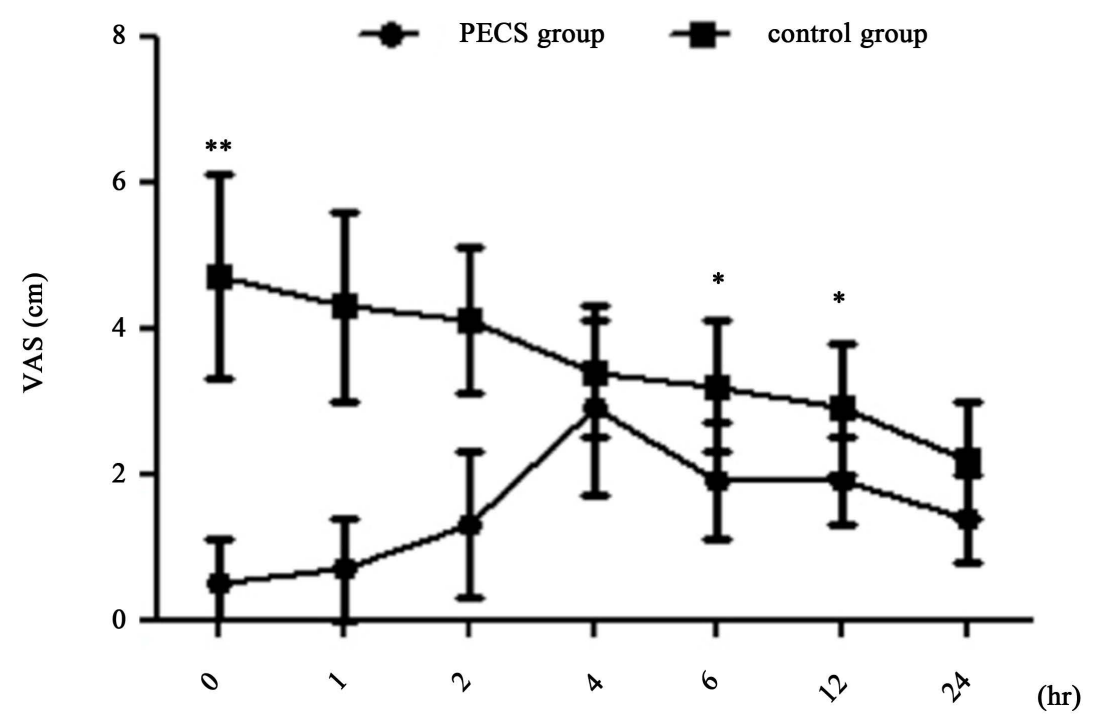

Figure 2. Postoperative VAS scores at $0,1,2,4,12,24$ hours postoperatively. ${ }^{\star} P<0.05$, ${ }^{* *} P<0.0001$.

\section{Discussion}

The VAS scores and the amount of additional acetaminophen $(1 \mathrm{~g})$ used within 24 after the operation were significantly lower in the PECS group than in the control group at all postoperative time periods. Compared with only general anesthesia alone, the combination of general anesthesia and regional anesthesia has the following benefit: 1) enhanced recovery after surgery, 2) reduction of 
postoperative mortality and morbidity, 3) reduced incidence of surgical site infection, 4) reduced incidence of cancer recurrence [8] [9] [10] [11].

Both TEB and TPVB provide effective perioperative analgesia for breast cancer surgery. However, we have encountered some problems using both blocks. The TEB is performed using landmark technique, which is not always reliable, and there are also hemodynamic changes induced by sympathetic nervous system block. TPVB is a difficult block to perform because the injection site is deep. Therefore, it is not easy for us to perform these blocks. PECS block is easier in comparison because the injection point is shallower and the supine position is used, whereas the position in TEB and TPVB is lateral or prone.

A half-life of levobupivacaine is not thought to be over 12 hour. Therefore, the VAS score at 24 hours after the operation also showed me an importance of prevent analgesia. What we are saying is that decreasing the development of central sentitization attenuatess postoperative pain, decrease analgesic consumption, and enhances recovery [12].

This study has some limitations. The data were collected retrospectively and patients were not randomized. All PECS blocks were performed using the same methods (e.g., volume and concentration of levobupivacaine), but it is currently unclear whether these methods are correct. We chose the volume and concentration of local anesthetic according to an original regimen [6], but several studies have reported using different regimens [13] [14]. Before we assessed the quality of the block, we have inducted general anesthesia. Thus, we could not investigate the range of analgesic. We also want to investigate the incidence of postoperative chronic pain. However we cannot get in touch with all patients. PECS block cannot anesthetize the internal mammary area. We manage this problem by performing a transversus thoracic muscle plane block (TTP) block [15], which anesthetizes the internal mammary are via injection of a local anesthetic in the TTP. In the future, some standardized prospective randomized trials are needed to investigate these various issues.

\section{Conclusions}

The PECS block showed lower visual analog scale pain scores at $0,1,2,4,6,12$, 24 hours after the operation. Moreover, the PECS block was lower the number of additional analgesic drugs during the first 24 hours after surgery.

We recommend PECS block for modified radical mastectomy surgery.

\section{References}

[1] Gärtner, R., Jensen, M.B., Nielsen, J., Ewertz, M., Kroman, N. and Kehlet, H. (2009) Prevalence of and factors Associated with Persistent Pain Following Breast Cancer Surgery. JAMA, 302, 1985-1992. https://doi.org/10.1001/jama.2009.1568

[2] Wijayasinghe, N., Andersen, K.G. and Kehlet, H. (2014) Neural Blockade for Persistent Pain after Breast Cancer Surgery. Regional Anesthesia and Pain Medicine, 39, 272-278. https://doi.org/10.1097/AAP.0000000000000101

[3] Scjnabel, A., Reichl, S.U., Kranke, P. and Pogatzki-Zahn, P.K. (2010) Efficacy and safety of Paravertebral Blocks in Breast Surgery: A Meta-Analysis of Randomized 
Controll Trials. British Journal of Anaesthesia, 105, 842-852. https://doi.org/10.1093/bja/aeq265

[4] Sundarathiti, P., Pasutharnchat, K., Kongdan, Y. and Suranutkarin, P. (2005) Thoracic Epidural Anesthesia with $0.2 \%$ Ropivacaine in Combination with Ipsilateral Brachial Plexus Block for Modified Radical Mastectomy. Journal of the Medical Association of Thailand, 88, 513-320.

[5] Blanco, R. (2011) The "Pecs Block": A Novel Technique for Privyding Analgesia after Breast Surgery. Anaesthesia, 66, 847-848. https://doi.org/10.1111/j.1365-2044.2011.06838.x

[6] Blanco, R., Fajardo, M. and Parra Maldonado, T. (2012) Ultrasound Descrytion of PecsII (Modified PecsI): A Novel Approach to Breast Surgery. Revista Española de Anestesiología y Reanimación, 59, 470-475.

https://doi.org/10.1016/j.redar.2012.07.003

[7] Bashandy, G.M.N. and Abbas, D.N. (2015) Pectoral Nerves I and II Blocks in Multimodal Analgesia for Breast Cancer Surgery. Regional Anesthesia and Pain Medicine, 40, 68-74. https://doi.org/10.1097/AAP.0000000000000163

[8] Fearon, K.C., Ljungqvist, O., Von Meyenfeldt, M., Revhaug, A., Dejong, C.H., Lassen, K., Nygren, J., Hausel, J., Soop, M., Andersen, J. and Kehlet, H. (2005) Enhanced Recovery after Surgery: A Consensus Review of Clinical Care for Patients Undergoing Colonic Resection. Clinical Nutrition, 24, 466-477. https://doi.org/10.1016/j.clnu.2005.02.002

[9] Rodgers, A., Walker, N., Schug, S., McKee, A., Kehlet, H., van Zundert, A., Sage, D., Futter, M., Saville, G., Clark, T. and MacMahon, S. (2000) Reduction of Postoperative Mortality and Morbidity with Epidural or Spinal Anaesthesia: Results from Overview of Randomised Trials. BMJ, 16, 321.

[10] Chang, C.C., Lin, H.C., Lin, H.W. and Lin, H.C. (2010) Anesthetic Management and Surgical Site Infections in Total Hip or Knee Replacement: A Population-Based Study. Anesthesiology, 13, 279-284. https://doi.org/10.1097/ALN.0b013e3181e2c1c3

[11] Biki, B., Mascha, E., Moriarty, D.C., Fitzpatrick, J.M., Sessler, D.I. and Buggy, D.J. (2008) Anesthetic Technique for Radical Proatatectomy Surgery Affects Cancer Recurrence: A Retrospective Analysis. Anesthesiology, 109, 180-187. https://doi.org/10.1097/ALN.0b013e31817f5b73

[12] Dioone, R. (2000) Preemptive vs Preventive Analgesia: Which Approach Improves Clinical Outcomes? Compendium of Continuing Education in Dentistry, 21, 48, 51 54.

[13] Ueshima, H. and Kitamura, A. (2015) Blocking of Multiple Anterior Branches of Intercoatal Nerves (Th2-6) Using a Transversus Thoracic Muscle Plane Block. Regional Anesthesia and Pain Medicine, 40, 388. https://doi.org/10.1097/AAP.0000000000000245

[14] Fujiwara, A., Komasawa, N. and Minami, T. (2014) Pectoral Nerves (PECS) and Intercostal Nerve Block for Cardiac Resynchronization Therapy Device Implantation. SpringerPlus, 5, 409. https://doi.org/10.1186/2193-1801-3-409

[15] Murata, H., Ichinomiya, T. and Hara, T. (2015) Pecs Block for Anesthesia in Breast Surgery of Elderly. Journal of Anesthesia, 29, 644.

https://doi.org/10.1007/s00540-015-1992-1 
Submit or recommend next manuscript to SCIRP and we will provide best service for you:

Accepting pre-submission inquiries through Email, Facebook, LinkedIn, Twitter, etc. A wide selection of journals (inclusive of 9 subjects, more than 200 journals)

Providing 24-hour high-quality service

User-friendly online submission system

Fair and swift peer-review system

Efficient typesetting and proofreading procedure

Display of the result of downloads and visits, as well as the number of cited articles Maximum dissemination of your research work

Submit your manuscript at: http://papersubmission.scirp.org/

Or contact ijcm@scirp.org 